\title{
Licitação sustentável: um estudo de caso das licitações de aquisições no município de Jaguaribe/CE
}

Sustainable bidding: a case study of biddings for acquisitions in the municipality of Jaguaribe/CE

\section{Leilane Kércia Barreto Soares ${ }^{1}$}

\section{RESUMO}

O governo é o principal responsável por fomentar boas práticas de compras sustentáveis, em virtude do grande volume de aquisições efetuadas. $\mathrm{O}$ artigo $3^{\circ}$ da Lei de Licitações, 8.666/93, apresenta em seu texto a obrigatoriedade do desenvolvimento nacional sustentável para toda a administração pública. Assim, objetivou-se analisar a existência de critérios sustentáveis nos processos licitatórios de aquisição do Município de Jaguaribe/CE. Trata-se de uma pesquisa descritiva e qualitativa dos editais licitatórios de aquisições, entre janeiro e setembro de 2017. Foram analisados 25 editais, bem como aplicado um questionário ao responsável pelo setor. Constatou-se que $72 \%$ dos editais analisados não atendem ao dispositivo legal do desenvolvimento nacional sustentável, dois editais trazem a obrigatoriedade da apresentação da Licença Ambiental e cinco descrevem alguns itens com critérios de sustentabilidade. É perceptível a deficiência da promoção do desenvolvimento nacional sustentável nas compras públicas da cidade, e deficiente a capacitação dos servidores.

Palavras-Chave: Licitação Sustentável. Desenvolvimento Nacional Sustentável.

\footnotetext{
$1 \quad$ Pós-graduada em Gestão Pública Municipal pela Universidade Estadual do Ceará (Uece). Pós-graduada em Gestão Financeira, Auditoria e Controladoria pela Universidade Vale do Salgado (Univs). Pós-graduada em Gestão em Saúde pela Universidade Estadual do Ceará (Uece). Pós-graduanda em Direito Administrativo e Gestão Pública pela Universidade Regional do Cariri (Urca). Graduada em Ciências Biológicas e em Administração Pública, ambas pela Universidade Estadual do Ceará (Uece). Graduanda em Ciências Contábeis pela Universidade de Ensino Superior de Maringá (Unicesumar). Funcionária pública do município de Jaguaribe, estado do Ceará. E-mail: leila_kercia@hotmail.com
} 


\section{ABSTRACT}

The government is the main responsible for promoting good sustainable purchasing practices, due to the large volume of acquisitions made. Article $3^{\circ}$ of the Bidding Law, 8,666/93, presents in its text the mandatory sustainable national development for the entire public administration. Thus, the objective was to analyze the existence of sustainable criteria in the bidding processes for the acquisition of the Municipality of Jaguaribe / CE. This is a descriptive and qualitative research of bidding notices for acquisitions, between January and September 2017. 25 bidding notices were analyzed, as well as a questionnaire applied to the person that was responsible for the sector. It was found that $72 \%$ of the bidding notices do not comply with the legal requirements of sustainable national development, two bidding notices make it mandatory to present the Environmental License and five bidding notices describe some items of sustainability criteria. There is a noticeable deficiency in promoting sustainable national development in public acquisition in the city, and the skill of civil servants is deficient.

Keywords: Bidding. Sustainable National Development. Environmental License. Sustainability.

Recebido: 10-08-2020

Aprovado: 07-10-2020

\section{INTRODUÇÃO}

$\mathrm{Na}$ atual conjuntura do cenário econômico mundial, as questões ambientais tornam-se centro de discussões dos governos devido o consumismo e o crescente processo industrial. Assim, faz-se necessário não só o desenvolvimento de políticas públicas voltadas para o desenvolvimento sustentável, como também o estímulo ao consumo consciente. Essa nova forma de consumo não deve partir apenas da sociedade civil, mas, princi- 
palmente, dos órgãos públicos, em suas aquisições, contratações de serviços ou construções de obras.

As compras públicas devem ser realizadas através de licitações, de acordo com a Lei 8.666/93, que garante a isonomia entre todos os interessados e a escolha da proposta mais vantajosa para o município (BRASIL, 1993). Esta lei teve seu artigo $3^{\circ}$ alterado pela Lei 12.349 , em 15 de dezembro de 2010, para atender as novas demandas da sociedade em relação a sustentabilidade, foi incluído em seu texto original a obrigatoriedade da promoção do desenvolvimento nacional sustentável (BRASIL, 2010b). Nesse cerne, entram em pauta elementos como durabilidade e eficiência dos materiais e a economicidade em harmonia com o meio ambiente.

Para o atendimento do que se pede no novo artigo $3^{\circ}$ da lei de licitações, é indispensável uma adequação das cláusulas dos editais, bem como descrição dos itens que possam promover o desenvolvimento nacional sustentável.

Diante do relato acima, questiona-se: quais os critérios utilizados nas licitações de aquisição do município de Jaguaribe para promoção do Desenvolvimento Nacional Sustentável, conforme determinação do artigo $3^{\circ}$ da Lei 8.666/93?

Nesta conjuntura, o presente trabalho tem como objetivo geral analisar o uso dos critérios de sustentabilidade, nos editais e nas especificações técnicas dos itens, junto aos processos licitatórios de aquisição do Município de Jaguaribe/CE. Como objetivos específicos: verificar a viabilidade da inserção de cláusulas nos editais e nos contratos referentes à sustentabilidade; e estudar os principais entraves para uma aplicabilidade mais efetiva dos critérios e práticas de compras sustentáveis no município pesquisado.

Esse estudo se justifica pelo desenvolvimento econômico, industrial e tecnológico acelerado, que aumenta a destruição do meio ambiente. Então, se faz importante analisar se as aquisições municipais estão contribuindo para o desenvolvimento sustentável, por meio da inserção de cláu- 
sulas com critérios sustentáveis, atitudes relevantes para a manutenção do meio ambiente em condições adequadas para as futuras gerações.

\section{REFERENCIAL TEÓRICO}

\subsection{DESENVOLVIMENTO SUSTENTÁVEL}

Uma das grandes preocupações mundiais são as questões ambientais. As mudanças climáticas, causadas pela degradação ambiental, vem mobilizando todos os países para a elaboração de projetos voltados ao desenvolvimento sustentável. De acordo com Nascimento (2012), desenvolvimento sustentável é aquele que atende às necessidades do presente sem comprometer as necessidades das futuras gerações, com qualidade de vida para todos.

O conceito de desenvolvimento sustentável é um instrumento para o crescimento, pois faz a junção do desenvolvimento econômico, com a proteção do ambiente e com justiça social, sendo seus valores reconhecidos pelos governos democráticos e os movimentos políticos de todo o mundo (LIMA; FROTA; ARAÚJO; FONTENELE, 2017).

O Estado tem a possibilidade de intervir nas questões ambientais do país, com a elaboração de normas a serem seguidas e desenvolvidas por empresas e pela própria administração pública, para garantir que sua produção e prestação de serviços sejam pautadas na preocupação com meio ambiente. Segundo Cavalcanti (2003) é primordial que as políticas governamentais referentes ao desenvolvimento sustentável sejam projetadas para garantir o bem-estar dessa geração, visando a garantia de recursos naturais para as gerações futuras. As ações governamentais devem abordar primeiramente o uso sustentável da natureza, junto com ferramentas que possam corrigir os desequilíbrios socioeconômicos do bem estar da sociedade.

Para Oliveira (2008), a Gestão Ambiental em si, é composta por medidas que identificam os problemas ambientais e que são provenientes 
das atividades de produção de uma instituição, podendo citar a poluição e, principalmente, o desperdício. Com isso, torna-se necessário a adoção de novos métodos capazes de diminuir ou mesmo erradicar os danos causados à natureza.

Nesse mesmo cerne, entra em discussão a definição de responsabilidade socioambiental, que, para Leal (2011), Responsabilidade Socioambiental é o exercício da ética e da cidadania visando o respeito à vida em todas as suas formas.

As organizações públicas não devem se responsabilizar somente pela elaboração de políticas voltadas para o setor econômico privado, é necessário implantar medidas dentro das unidades administrativas que estejam voltadas ao desenvolvimento sustentável. A nova cultura organizacional a ser seguida deve ser pautada na economicidade, na redução e reutilização dos materiais de consumo utilizados. Também é salutar enfatizar a necessidade de seguir as normas impostas pelas legislações vigentes sobre adoção de critérios sustentáveis.

\subsection{LICITAÇÃO SUSTENTÁVEL}

Antes de abordar o tema Licitação Sustentável, é necessário fazer um breve estudo sobre licitação e suas principais características. Araújo (2001, p. 19) explica que:

Licitação é o procedimento administrativo prévio feito pela administração pública antes da sua contratação com terceiros, para a aquisição de bens ou execução de obras e serviços necessários ao atendimento das necessidades públicas, bem como para a alienação de seus bens.

Fernandes (2013), completa a definição acima descrevendo que esse processo é indispensável para garantir a isonomia entre os interessados na contratação, selecionar a proposta mais vantajosa para a adminis- 
tração pública e promover o desenvolvimento sustentável, de acordo com os critérios definidos.

Os conceitos expostos não se contradizem, mas se completam, já que o conceito não muda e a exigência de obediência dos preceitos legais permanece. A lei que rege as licitações e contratos públicos é a 8.666, promulgada em 21 de junho de 1993. Após essa data foram publicadas outras leis para alterações de alguns de seus artigos (BRASIL, 1993).

De acordo com a Lei 8.666/93, Lei de Licitações, são cinco as modalidades de licitação, cada uma com características próprias, classificadas e escolhidas de acordo com o objeto licitado, são elas: concorrência pública, tomada de preços, carta convite, concurso e leilão. Fazendo um breve resumo de cada uma dessas modalidades pode-se descrever: na concorrência pública, qualquer interessado pode participar da etapa inicial que é a fase de habilitação, ou seja, atender as qualificações exigidas no edital, os aptos passam para a análise da proposta de preços. Nesta modalidade não há limite de valor. A modalidade tomada de preços é restrita aos interessados que atendam aos requisitos exigidos para o cadastramento junto à licitante até três dias úteis antes da data de realização do certame, observando sempre as exigências contidas em cada edital, seguindo inicialmente com a análise dos documentos de habilitação e posteriormente com a análise de propostas de preços (BRASIL, 1993).

O convite é um processo mais simplificado, com um curto prazo para a sua realização, cinco dias úteis. Nesta modalidade são convidadas no mínimo três empresas para participar do certame, podendo ser cadastradas ou não na unidade administrativa, e os demais interessados podem participar, contanto que manifestem interesse na participação até 24 (vinte e quatro) horas antes do certame (BRASIL, 1993).

Por sua vez, o concurso é a modalidade para a escolha de profissional para trabalho técnico, científico ou artístico e os vencedores podem ter seu trabalho premiado ou remunerado, dependendo do que consta no edital. E, por último, o leilão, modalidade de licitação que a administra- 
ção pública utiliza para a venda de bens móveis inservíveis ou produtos legalmente apreendidos ou penhorados, vence o certame quem oferecer o maior valor para a compra dos produtos (BRASIL, 1993).

A Lei 10.520 , de 16 de julho de 2002, institui uma nova modalidade de licitação denominada pregão, destinado à aquisição de bens e serviços comuns, sem limite de valor. Nesta modalidade, há uma inversão das fases, primeiramente faz-se a análise das propostas de preços e posteriormente a verificação dos documentos de habilitação, sempre baseado no edital de convocação. Um diferencial do pregão é a possibilidade de os representantes das empresas ofertarem lances verbais, reduzindo os valores inicialmente trazidos (BRASIL, 2002).

Os processos de licitação devem seguir os princípios constitucionais e os princípios expostos no próprio texto da lei que rege as licitações e os contratos públicos. De acordo com o teor do artigo 37 da Constituição Federal, promulgada em 1988, "a administração pública direta e indireta de qualquer dos Poderes da União, dos Estados, do Distrito Federal e dos Municípios obedecerá aos princípios de legalidade, impessoalidade, moralidade, publicidade e eficiência" (BRASIL, 1988).

Os outros princípios norteadores das licitações estão descritos no artigo $3^{\circ}$ da Lei 8.666, de 21 de junho de 1993, que diz:

\begin{abstract}
A licitação destina-se a garantir a observância do princípio constitucional da isonomia, a seleção da proposta mais vantajosa para a administração e a promoção do desenvolvimento nacional sustentável e será processada e julgada em estrita conformidade com os princípios básicos da legalidade, da impessoalidade, da moralidade, da igualdade, da publicidade, da probidade administrativa, da vinculação ao instrumento convocatório, do julgamento objetivo e dos que lhes são correlatos (BRASIL, 1993).
\end{abstract}

Em 2010 houve alteração da redação desse artigo pela Lei n ${ }^{\circ} 12.349$, de 15 de dezembro, quando passou a ser obrigatória a promoção do desen- 
volvimento nacional sustentável, até então em desuso para as contratações de aquisições, ou para obras e prestação de serviços (BRASIL, 2010b). A promoção do desenvolvimento nacional sustentável é feita com o uso de licitações sustentáveis, que assim Cypreste (2013, p. 40), descreve:

\begin{abstract}
A licitação sustentável se preocupa em estimular a redução de consumo, a fim de se reduzir a quantidade de resíduos além de se evitar desperdícios, pois assim se diminui a necessidade de produzir mais, e consequentemente, a sobrecarga ao meio ambiente no que se refere aos insumos por ele fornecidos para produção. Esse procedimento se preocupa, ainda, com a reutilização do material e a reciclagem; além da saúde humana e preservação do meio ambiente, levando em conta a sustentabilidade não só dos produtos, mas também de todo processo de produção, buscando maior eficiência.
\end{abstract}

Esta permite atender as necessidades do consumidor final, que seria o órgão ou a entidade pública, oferecendo grandes benefícios para o meio ambiente e para a sociedade.

Conforme relata Pinheiro (2013), os governos têm papel primordial de criar leis e regulamentos, mas, também, sendo os consumidores mais ativos do mercado, têm a obrigação de liderar dando exemplos, praticando o que prega a lei. Para isso, é necessário incorporar às suas contratações e aquisições exigências socioambientais, ainda que poucas, de forma a regulamentar e incentivar práticas de compras públicas sustentáveis nos órgãos públicos.

A próxima subseção apresenta um breve resumo do que são licitações sustentáveis, à luz das legislações vigentes. 


\subsection{LEGISLAÇÃO DAS LICITAÇÕES SUSTENTÁVEIS}

A Constituição Federal proclamada em 1988, no seu artigo 225 prevê que todos têm direito ao meio ambiente ecologicamente equilibrado e essencial à sadia qualidade de vida. Impõe ao Poder Público e à coletividade o dever de defendê-lo e preservá-lo para a presente e futura geração (BRASIL, 1988). Assim, nesse artigo, o Governo Federal obriga a todos os poderes públicos garantir a defesa do meio ambiente, com a geração de projetos voltados para a manutenção ambiental, e isso pode ser realizado por meio de compras públicas de forma sustentável.

Como relatado na seção anterior, o artigo $3^{\circ}$ da Lei de Licitações $8.666 / 93$ foi alterado pela Lei $12.349 / 10$, a qual inclui no texto constitucional a obrigatoriedade do desenvolvimento nacional sustentável para toda a administração pública, contratantes e contratados.

Após esta lei, houve a publicação de três decretos, apenas no âmbito da administração pública federal, que estabelecem critérios e práticas para a promoção do desenvolvimento nacional sustentável.

Em 5 de junho de 2012, foi instituído o decreto 7.746 que estabelece critérios e práticas para a promoção do desenvolvimento nacional sustentável, contudo, somente nas contratações realizadas pela administração pública federal direta, autárquica e fundacional e pelas empresas estatais dependentes (BRASIL, 2012a). E, em 23 de outubro de 2017, teve seu texto alterado pelo Decreto 9.178 (BRASIL, 2017). Desta forma, define como critérios e práticas de sustentabilidade, entre as quais relaciona:

I - baixo impacto sobre recursos naturais como flora, fauna, ar, solo e água;

II - preferência para materiais, tecnologias e matérias-primas de origem local;

III - maior eficiência na utilização de recursos naturais como água e energia;

IV - maior geração de empregos, preferencialmente com mão de obra local; 
$\mathrm{V}$ - maior vida útil e menor custo de manutenção do bem e da obra;

VI - uso de inovações que reduzam a pressão sobre recursos naturais;

VII - origem sustentável dos recursos naturais utilizados nos bens, nos serviços e nas obras; e

VIII - utilização de produtos florestais madeireiros e não madeireiros originários de manejo florestal sustentável ou de reflorestamento (BRASIL, 2012a).

Os Decretos 7.840 e o 7.843 , ambos de 12 de novembro de 2012, complementaram o artigo $3^{\circ}$ da Lei 8.666/93, que estabelece a aplicação de margem de preferência em licitações para aquisição de perfuratrizes e patrulhas mecanizadas, na esfera pública federal (BRASIL, 2012b, 2012c).

A Lei 11.079, de 30 de dezembro de 2004, que institui normas gerais para licitação e contratação de Parceria Público-Privada (PPP) no âmbito da administração pública, traz em seu artigo $10^{\circ}$, inciso VII, a necessidade de apresentação prévia da licença ambiental ou expedição das diretrizes para o licenciamento ambiental do empreendimento, na forma do regulamento, sempre que o objeto do contrato exigir (BRASIL, 2004). Essa é uma forma de garantir que as empresas participantes preservem o patrimônio ambiental do país. Percebe-se que essa exigência foi instituída antes da alteração do artigo $3^{\circ}$ da Lei de Licitações, o que denota que a preocupação ambiental provém de longas datas.

Vários órgãos federais estabelecem normas por meio de portarias com o intuito de promover e estimular o desenvolvimento sustentável e o consumo consciente em suas repartições de trabalho. Pode-se citar a Portaria 61, de 15 de maio de 2008, do Ministério do Meio Ambiente, que estabelece práticas de sustentabilidade ambiental a serem observadas por este Ministério, bem como suas entidades vinculadas para as compras públicas sustentáveis. Optando por fornecedores e produtos que, comprovadamente, causem o menor prejuízo ao ambiente, sempre observando 
a necessidade de justificativa e especificações técnicas para unir os interesses da administração pública à preservação do ambiente, garantindo, também, o bem-estar social (BRASIL, 2008).

Outro exemplo é a Portaria 23, de 12 de fevereiro de 2015, do Ministério de Planejamento, Orçamento e Gestão, neste instrumento, o qual institui boas práticas de gestão e uso de energia elétrica e de água nos órgãos e entidades da Administração Pública Direta. Sempre com atenção ao monitoramento de bens e serviços, fazendo com que as entidades adotem providências necessárias a executar as boas práticas expostas acima, bem como o desenvolvimento de campanhas de conscientização (BRASIL, 2015).

Como se pode inferir, na esfera federal existem várias normas e diretrizes que auxiliam os agentes públicos na elaboração de licitações que sejam pautadas no desenvolvimento nacional sustentável. Inexistindo, no âmbito municipal, qualquer Lei ou Decreto que crie normas ou diretrizes para elaboração de licitações sustentáveis, como é exigido no artigo $3^{\circ}$ da lei de licitações e contratos.

Em âmbito estadual, a Resolução Administrativa 3/2019 do TCE/ CE (Tribunal de Contas do Estado do Ceará), estabelece critérios a serem observados de sustentabilidade ambiental para a contratação de serviços ou obras e para a aquisição de bens (CEARÁ, 2019).

Sabe-se que uma lei demanda certo tempo para que se torne realmente efetiva, principalmente diante da complexidade dos dois temas em questão, licitações e sustentabilidade. Para isso, são necessários instrumentos que norteiem e que facilitem o trabalho dos administradores públicos que atuam na área, fazendo com que os processos de aquisição sustentáveis possam ser efetuados como regra e não como exceção nas compras públicas. 


\subsection{PROCESSAMENTO DE UMA LICITAÇÃO SUSTENTÁVEL}

Conforme o Guia Nacional de Contratações Sustentáveis, da Advocacia Geral da União (AGU), antes de mais nada as licitações devem ser devidamente planejadas, tendo como uma de suas premissas a responsabilidade ambiental e incluindo critérios que garantam uma redução dos impactos ambientais, no presente e no futuro. Planejar é a melhor maneira de assegurar que as compras sejam efetuadas de forma consciente. A escotha dos itens e sua correta descrição é o primeiro passo para a realização de uma licitação sustentável (BRASIL, 2020).

Para Furtado (2012), no planejamento é imprescindível que o gestor conheça o objeto a ser licitado e proceda um levantamento verificando sua disponibilidade no mercado, observando o ciclo de vida de produtos para que possa delimitar a correta especificação do item desejado. Nesse cenário, traz ao administrador público a obrigação de reforçar outros dois grandes princípios: o da economicidade e o da razoabilidade, pois nem sempre o mais barato é o melhor. Analisar o custo-benefício do produto é o principal ponto de partida para a aquisição de bens sustentáveis.

De acordo com Barroso Filho (2012), mesmo que os custos dos produtos ecologicamente corretos ainda sejam altos, se tornando uma das principais barreiras para sua aquisição, o incentivo e o uso são importantes. Pois com o passar do tempo e das exigências públicas, as empresas se adequarão e, por conseguinte, reduzirão os preços dos produtos. Ao final, combinar-se-ão o desempenho econômico e a preservação do ambiente.

Os critérios de sustentabilidade a serem adotados devem ser objetivos e claros, para que não caiam em favorecimentos indevidos. Para a aquisição dos bens que atendam aos quesitos de sustentabilidade, é necessário haver uma comprovação documental para mostrar que a escolha é a mais viável para a administração pública e para o desenvolvimento socioambiental. Após a seleção dos itens sustentáveis a serem adquiridos, cabe 
decidir a documentação a ser solicitada aos licitantes, tais como licenças ambientais, certificados, documentos e laudos.

Segundo o Guia Nacional de Contratações Sustentáveis, da Advocacia Geral da União (AGU), a inserção de critérios de sustentabilidade deve obrigatoriamente ser feita de modo claro e objetivo, atentando sobre a disponibilidade do mercado oferecer os produtos e a possibilidade de comprovação e verificação dos critérios fixados pelo órgão público executor do certame. A comprovação pode ser feita através de certificados, documentos comprobatórios, amostras, laudos, detalhes sobre descarte de embalagem, declarações, entre outros (BRASIL, 2020).

Após a fase de planejamento, elaboração e publicação do edital, com as cláusulas voltadas ao desenvolvimento sustentável, o procedimento licitatório sustentável segue normalmente como o de qualquer outra licitação. Apenas na entrega dos produtos que são verificadas se as especificações atendem ao objeto licitado. O setor responsável por fazer o recebimento e avaliação dos itens é, geralmente, o setor de compras.

\section{METODOLOGIA}

O presente estudo, em relação aos objetivos, consiste em uma pesquisa de natureza descritiva (PRODANOV; FREITAS, 2013), pois busca conhecer a utilização de licitações sustentáveis nas compras realizadas pelo Município de Jaguaribe em atendimento do artigo $3^{\circ}$ da Lei Licitações $\mathrm{N}^{\mathrm{o}} 8.666 / 93$.

Em relação à abordagem, é elaborada, predominantemente, de forma qualitativa, já que não se pretende numerar variáveis mas sim entender e descrever o conhecimento e o uso de Licitação Sustentável na Prefeitura Municipal de Jaguaribe, sem fazer uso de instrumentos estatísticos para isso (PRODANOV; FREITAS, 2013).

No que se refere aos procedimentos técnicos, trata-se de um levantamento de dados que busca conhecer os critérios adotados pelo Municí- 
pio em questão nas licitações de compras para atender o desenvolvimento nacional sustentável. Trata-se, também, de um levantamento de campo, por meio da aplicação de um questionário direto ao responsável pelo setor. Este instrumento foi utilizado para conhecer algumas particularidades do setor de licitações e as dificuldades encontradas para a elaboração de editais de compras que atendam aos critérios de sustentabilidade socioambiental.

Inicialmente, foi feita uma revisão bibliográfica na literatura sobre temas como desenvolvimento sustentável, licitações, licitações sustentáveis e a legislação que rege esses processos.

Posteriormente, foi pesquisado no site do Tribunal de Contas do Estado do Ceará (TCE-CE) os editais de licitação de compras do Município de Jaguaribe durante o período de janeiro a dezembro do ano de 2017, período selecionado por acessibilidade. Na pesquisa foram encontrados e analisados 25 editais, sendo todos da modalidade pregão presencial.

Após análise dos documentos coletados na internet, foi feita a aplicação de um questionário com perguntas abertas com o Técnico em Licitações responsável pela assessoria do setor de licitação do município, para aprofundar mais o conhecimento sobre o assunto em tela. Segundo Gil (2008), "esse tipo de questão possibilita ampla liberdade de resposta". Foi questionando sobre os principais aspectos que foram analisados nos editais extraídos da internet. Este instrumento foi aplicado com apenas uma pessoa do setor por questão de acessibilidade e por este ser o responsável pela análise dos editais elaborados no setor, bem como estar presente em toda operacionalização do certame.

O instrumento foi composto por duas questões, suficientes para explicar o tema, já que foi aplicado após análise documental dos editais. De acordo com Gil (2008), a quantidade de perguntas depende da complexidade do tema e devem ser rigorosamente necessárias para atingir os objetivos da pesquisa. 


\section{RESULTADOS E DISCUSSÕES}

Conforme mencionado na metodologia, a análise dos resultados foi realizada em duas etapas: análise documental e aplicação de questionário com o responsável do setor.

\subsection{ANÁLISE DOCUMENTAL}

Nessa etapa foram analisados os editais de compras de janeiro a setembro de 2017, que totalizou a soma de 25 editais de pregões, todos da forma presencial.

Nos editais foram analisadas as descrições de todos os materiais adquiridos (consumo e permanente) e as cláusulas referentes ao desenvolvimento nacional sustentável, especialmente os documentos de habilitação exigidos. Na Tabela 1 é possível verificar as licitações analisadas e a sua classificação:

Tabela 1: Relação das licitações de material de consumo e de material permanente

\begin{tabular}{c|l}
\hline \multicolumn{1}{c|}{ Número da Licitação } & \multicolumn{1}{c}{ Materiais de consumo } \\
\hline $\begin{array}{c}\text { PREGÃO PRESENCIAL } \\
04.01 .02 / 2017\end{array}$ & $\begin{array}{l}\text { Aquisição de material consumo (expediente, educativo e esporti- } \\
\text { vo, proteção, acondicionamento e embalagem) }\end{array}$ \\
\hline $\begin{array}{c}\text { PREGÃO PRESENCIAL } \\
13.01 .01 / 2017\end{array}$ & Aquisição de livros didáticos \\
\hline $\begin{array}{c}\text { PREGÃO PRESENCIAL } \\
19.01 .01 / 2017\end{array}$ & Aquisição de oxigênio para o hospital \\
\hline $\begin{array}{c}\text { PREGÃO PRESENCIAL } \\
23.01 .01 / 2017\end{array}$ & Aquisição de peças e serviços para a frota de veículos \\
\hline $\begin{array}{c}\text { PREGÃO PRESENCIAL } \\
26.01 .01 / 2017\end{array}$ & Aquisição de urnas funerárias \\
\hline $\begin{array}{c}\text { PREGÃO PRESENCIAL } \\
\text { 31.01.01/2017 }\end{array}$ & Aquisição de combustível perímetro de Fortaleza \\
\hline $\begin{array}{c}\text { PREGÃO PRESENCIAL } \\
\text { 31.01.02/2017 }\end{array}$ & $\begin{array}{l}\text { Aquisição de material consumo (limpeza, limpeza pesada, piscina, } \\
\text { copa e cozinha, processamento de dados, cartuchos e tonner) }\end{array}$ \\
\hline $\begin{array}{c}\text { PREGÃO PRESENCIAL } \\
15.02 .01 / 2017\end{array}$ & Aquisição de material esportivo \\
\hline
\end{tabular}


Tabela 1: Relação das licitações de material de consumo e de material permanente (continuação)

\begin{tabular}{|c|c|}
\hline $\begin{array}{l}\text { PREGÃO PRESENCIAL } \\
22.02 .03 / 2017\end{array}$ & Aquisição de pneus e câmaras de ar \\
\hline $\begin{array}{l}\text { PREGÃO PRESENCIAL } \\
07.03 .01 / 2017\end{array}$ & Aquisição de merenda escolar \\
\hline $\begin{array}{l}\text { PREGÃO PRESENCIAL } \\
09.03 .01 / 2017\end{array}$ & Aquisição de fardamento, rouparia e material serigráfico \\
\hline $\begin{array}{l}\text { PREGÃO PRESENCIAL } \\
10.03 .01 / 2017\end{array}$ & Aquisição de material gráfico \\
\hline $\begin{array}{l}\text { PREGÃO PRESENCIAL } \\
12.04 .01 / 2017\end{array}$ & $\begin{array}{l}\text { Aquisição de gêneros alimentícios para a Secretaria de Ação } \\
\text { Social }\end{array}$ \\
\hline $\begin{array}{l}\text { PREGÃO PRESENCIAL } \\
03.05 .02 / 2017\end{array}$ & Aquisição de material gráfico Secretaria de Ação Social \\
\hline $\begin{array}{l}\text { PREGÃO PRESENCIAL } \\
29.05 .01 / 2017\end{array}$ & Aquisição de material esportivo \\
\hline $\begin{array}{l}\text { PREGÃO PRESENCIAL } \\
08.06 .01 / 2017\end{array}$ & Aquisição de construção \\
\hline $\begin{array}{l}\text { PREGÃO PRESENCIAL } \\
08.06 .02 / 2017\end{array}$ & Aquisição de material serigráfico \\
\hline $\begin{array}{l}\text { PREGÃO PRESENCIAL } \\
12.09 .01 / 2017\end{array}$ & $\begin{array}{l}\text { Aquisição de peças para o equipamento de raio X do hospital } \\
\text { Municipal }\end{array}$ \\
\hline \multicolumn{2}{|r|}{ Materiais permanentes } \\
\hline $\begin{array}{l}\text { PREGÃO PRESENCIAL } \\
\text { 24.01.02/2017 }\end{array}$ & Equipamentos e material permanente para o Hospital \\
\hline $\begin{array}{l}\text { PREGÃO PRESENCIAL } \\
16.02 .02 / 2017\end{array}$ & $\begin{array}{l}\text { Equipamentos e material permanente para as Unidades da Atenção } \\
\text { Básica }\end{array}$ \\
\hline $\begin{array}{l}\text { PREGÃO PRESENCIAL } \\
\text { 22.03.01/2017 }\end{array}$ & Aquisição de material permanente para as diversas secretarias \\
\hline $\begin{array}{l}\text { PREGÃO PRESENCIAL } \\
14.09 .01 / 2017\end{array}$ & $\begin{array}{l}\text { Aquisição de material de informática para as Unidades Básicas de } \\
\text { Saúde }\end{array}$ \\
\hline $\begin{array}{l}\text { PREGÃO PRESENCIAL } \\
18.09 .01 / 2017\end{array}$ & Aquisição de equipamentos para as Unidades Básicas de Saúde \\
\hline $\begin{array}{l}\text { PREGÃO PRESENCIAL } \\
18.09 .02 / 2017\end{array}$ & Aquisição de equipamentos e material permanente para o Hospital \\
\hline $\begin{array}{l}\text { PREGÃO PRESENCIAL } \\
20.09 .02 / 2017\end{array}$ & $\begin{array}{l}\text { Aquisição de equipamento de raio X para Unidade de Pronto } \\
\text { Atendimento (UPA) }\end{array}$ \\
\hline
\end{tabular}

Fonte: Elaborado pela autora (2017).

Rev. Controle, Fortaleza, v.19, n.2, p. 390-420, jul./dez. 2021. 
Percebe-se que a grande maioria das licitações de compras realizadas no período estudado são materiais de consumo não duráveis, sendo poucas licitações para aquisição de material permanente. A maior parte dos recursos dos editais de material permanente foram provenientes de emendas parlamentares, que são transferências de recursos denominadas fundo a fundo, não cabendo aqui descrevê-las.

Dentre os editais analisados, apenas 2 (dois) solicitaram, nas condições de habilitação, a Licença Ambiental expedida por órgão competente. Os dois editais em questão foram: o Pregão Presencial 31.01.01/2017, para a aquisição de combustível no perímetro de Fortaleza/CE e o Pregão Presencial 19.01.01/2017, aquisição de gás oxigênio para uso medicinal. No caso, as licenças foram emitidas pela Semace (Superintendência Estadual do Meio Ambiente do Ceará), órgão do governo do estado do Ceará responsável pela liberação dessa documentação.

A exigência dessa documentação poderia ser interpretada como uma maneira de reduzir a competição entre os interessados, contudo, ao contrário disso, é uma forma de garantir que as empresas participantes estejam aptas a atuar de forma que os serviços prestados ou os produtos entregues não causem danos nem impactos ambientais.

Assim, verificou-se que o licenciamento ambiental é um instrumento importante de gestão da Administração Pública, sendo que, por meio dele, é possível exercer o controle das ações humanas sobre o ambiente por parte dos órgãos competentes de fiscalização. Todas as empresas e as atividades que usem recursos naturais ou que possam causar algum prejuízo ambiental estão sujeitas a essa exigência legal. Vale ressaltar que esse documento possui prazo de validade definido, e deve ser renovado sempre que sua validade expirar (BRASIL, 2004).

Continuando as análises, observou-se que 5 (cinco) editais destinados à compra de material e equipamentos permanentes, possuem, na descrição dos materiais, requisitos que atendem ao desenvolvimento sustentável e que reduzem os impactos causados na natureza. Nota-se que 
alguns deles não obtiveram sucesso na contratação e foi necessária a republicação, ou seja, os itens também foram repetidos. Assim, não houve uma grande quantidade de itens que incentivassem a sustentabilidade, apenas foram repetidos devido o fracasso de licitações anteriores.

Dos editais descritos acima, 7 itens (cadeiras fixas e longarinas) possuem a seguinte descrição:

A estrutura tem que possuir tratamento de superfície com fosfato de zinco, (executado em linha automática de oito tanques, sem uso de produtos clorados para desengraxe, e com posterior tratamento de efluentes, de acordo com as normas da Fepam-RS), proporcionando proteção contra corrosão e para uma melhor ancoragem da tinta, evitando assim o descolamento da mesma; A tinta utilizada para a pintura é em pó, do tipo híbrida (poliéster - epóxi), W-Eco, atendendo norma Europeia RoHS, isenta de metais pesados, na cor preto, com camada de 60 mícrons, onde todas as peças são curadas em estufa, à temperatura de $200 \varnothing$ C. Poltrona baseada nas normas NR17 Norma Regulamentadora do Ministério do Trabalho, que trata da ergonomia; e da NBR 13962 - da Associação Brasileira de Normas Técnicas (ABNT), apresentar certificado. Dimensões Aproximadas: Largura do assento: $460 \mathrm{~mm}$; Profundidade do assento: $400 \mathrm{~mm}$; Largura do encosto: $460 \mathrm{~mm}$; Altura do encosto: $260 \mathrm{~mm}$; Profundidade total da cadeira: $525 \mathrm{~mm}$; Altura total da cadeira: $825 \mathrm{~mm}$; Altura do assento: $450 \mathrm{~mm}$; Largura total da cadeira: $545 \mathrm{~mm}$. Montagem: inclusa (JAGUARIBE, 2017, p. 17).

De acordo com Aguiar, Novaes e Guarino (2002), a poluição química é, sem dúvida, a que causa os problemas ambientais mais sérios, afetando até a saúde dos seres vivos. Isso se dá por meio de produtos cloratos para enxágue, bem como os metais pesados, ambos relatados na descrição do item acima. Asseguram que algumas dessas substâncias são altamente tóxicas, podendo ser transferidas ao longo de toda a cadeia alimentar dos seres vivos. Assim, se faz necessário reduzir ao máximo o uso desses produtos. Mesmo que de forma incipiente, essas exigências já constituem 
como um salto para a disseminação dos cuidados ambientais, e a preocupação da gestão pública com a necessidade da proteção ambiental.

De acordo com Seresp (2006 apud ARAÚJO; SILVA; WADA; OLIVEIRA FILHO, 2008), o tratamento de efluentes e posterior utilização desta água na própria indústria reduz consideravelmente os custos de produção, por isso muitas indústrias estão investindo massivamente nessa área. E a cada vez mais a gestão pública deve intensificar a solicitação de materiais que sejam produzidos a partir de água tratada de efluentes, para forçar as indústrias a se adequar e aprimorar essa prática.

Melo (2019), em sua pesquisa, reforça que os setores não sabem elaborar nem identificar especificações que busquem o menor impacto ambiental, relacionado com o custo-benefício do produto, talvez por falta de conhecimento técnico dos requisitos de sustentabilidade.

Para fomentar o tema, o Estado do Ceará instituiu o "Selo Empresa Sustentável", que visa destacar empresas que durante o processo produtivo investem no meio ambiente (CEARÁ, 2019). Ainda é incipiente se comparado aos desastres ambientais que a atividade produtiva causa, porém, não deixa de ser um pequeno avanço de estímulos às empresas. Então, quanto mais empresas atenderem aos parâmetros de sustentabilidade, mais fácil será aos órgãos públicos contratarem empresas que tenham responsabilidade ambiental como pilar de produção.

Outro item que promove a sustentabilidade é um armário, que foi adquirido pelo hospital municipal, com a seguinte descrição:

Armário tipo vitrine. Especificação: Armário Vitrine com 02 portas de vidro. Armário de aço montável, possui duas portas de abrir com reforços internos tipo Omega, puxador estampado na própria porta no sentido vertical, possui sistema de cremalheira para regulagem das prateleiras a cada $50 \mathrm{~mm}$, com 1 prateleira fixa para travamento das portas e 3 reguláveis, fechadura cilíndrica com chaves tipo yale. Kit pé regulável. Estrutura: Todo confeccionado em chapa de aço n $24(0,60 \mathrm{~mm})$. Acabamento: Tratado pelo processo anti-corrosivo à base de fosfato de 
zinco e pintura em esmalte sintético com camada de 30 a 40 mícrons com secagem em estufa a $120{ }^{\circ} \mathrm{C}$ na cor branca. Capacidade: $25 \mathrm{~kg}$ por prateleira (bem distribuídos). Dimensões: Alt $\times$ Larg $\times$ Prof. Externas: $1700 \times 750 \times 400 \mathrm{~mm}$. Certificado de Regularidade do IBAMA (Certificado que comprova a regularidade no Cadastro de Atividades Potencialmente Poluidoras). Laudo Técnico de Órgão competente referente às normas NR 17-ERGONOMIA, fornecido por profissionais credenciados (JAGUARIBE, 2017, p. 27, grifo nosso).

O Ibama (Instituto Brasileiro do Meio Ambiente e dos Recursos Naturais Renováveis) é uma autarquia federal dotada de personalidade jurídica de direito público, com autonomia administrativa e financeira (BRASIL, 2018). De acordo com o artigo $2^{\circ}$, inciso IV da Instrução Normativa $\mathrm{N}^{\circ} 6$ do IBAMA, de 15 de março de 2013, o Cadastro Técnico Federal de Atividades Potencialmente Poluidoras e Utilizadoras de Recursos Ambientais (CTF/PREGÃO PRESENCIAL) é um cadastro que contém o registro das pessoas físicas e jurídicas que, em âmbito nacional, desenvolvem atividades potencialmente poluidoras e utilizadoras de recursos ambientais (BRASIL, 2013, p. 2).

A existência dessa documentação é verificada no momento da entrega do produto à entidade compradora. Neste momento, além das especificações serem minuciosamente analisadas, a parte documental e legal dos materiais também é conferida.

$\mathrm{Na}$ visão de Vicentini (2019), alguns empreendedores podem ver a licença ambiental como inimiga do desenvolvimento econômico, outros, já a veem como uma garantia ao meio ambiente e um cumprimento legal. Porém, ele destaca que esse documento é uma garantia de que os prováveis impactos ambientais sejam amenizados, e reforça que a licença proporciona planejamento, racionalidade e responsabilidade à operacionalização das empresas.

De todos os editais analisados, 18 (dezoito) não apresentam nenhuma cláusula que buscasse o desenvolvimento nacional sustentável, também não 
apresentando, na descrição de seus itens, algum benefício ambiental.

Os editais analisados de compras de pneus, de pilhas e baterias não possuem informações quanto ao descarte correto desse material após o uso. Para esse tipo de material é imprescindível estabelecer critérios para a Logística Reversa (LR), que foi instituída em 2010 pela Lei 12.305, na Política Nacional de Resíduos Sólidos, inciso III, artigo $8^{\circ}$ do capítulo III. As empresas produtoras de diversos materiais, inclusive pilhas e baterias, que são altamente poluentes, devem desenvolver e implementar sistemas para o retorno dos produtos, após serem consumidos (BRASIL, 2010a).

Através da pesquisa, percebeu-se que $72 \%$ dos editais das licitações analisadas do Município de Jaguaribe não atendem ao dispositivo da lei, que é a garantia do desenvolvimento nacional sustentável nas compras governamentais. A única exigência documental detectada foi a Licença Ambiental, em apenas 2 editais, apesar de pouco, isso já se torna um passo importante para o uso do desenvolvimento sustentável. Dos 7 editais, qual seja $28 \%$, que possuíam algum critério sustentável em seus itens, tiveram que ser republicados pois os primeiros não obtiveram sucesso, o que pode ter alterado a quantidade de itens que possuem critérios de preservação ambiental em sua descrição.

\subsection{APLICAÇÃO DE QUESTIONÁRIO}

Nessa etapa da pesquisa, após análise dos editais, foi feita a aplicação de um pequeno questionário ao Técnico em Licitações do setor e que presta serviços de staff na área de Licitações deste município.

Ao ser questionado sobre a participação dos integrantes do setor de licitações em cursos de capacitação sobre compras sustentáveis, a resposta obtida foi:

Os cursos nessa área são escassos. Ainda é um tema novo para a administração pública e poucos gestores se preocupam na compra de produtos sustentáveis, a maior preocupação são os valores dos produtos. Quanto menor o valor, melhor. Pouco importa 
se os produtos serão de curta duração, se seu uso irá poluir o ambiente ou se em sua produção foram respeitadas as diretrizes de sustentabilidade.

A falta de capacitação e conhecimento é um dos fatores que mais influenciam as contratações sustentáveis. Lucena (2016), em estudo realizado, afirma que ainda existe um grande desconhecimento sobre o tema licitação sustentável, e que não basta apenas os integrantes responsáveis pelas compras terem esse conhecimento, é imprescindível a iniciativa e o planejamento dos gestores.

A próxima pergunta questionava se o único problema seria a falta de capacitação dos integrantes do setor de licitações. Obteve-se a seguinte resposta:

Não, os atores mais importantes envolvidos na correta aplicação do desenvolvimento nacional sustentável, descrita no artigo $3^{\circ}$ da lei $8.666 / 93$, são os gestores das secretarias, pois eles quem devem saber qual a demanda da sua secretaria, descrevem os produtos, enviam essa demanda para o setor de compras (responsável pela coleta de preços) e, só após essas etapas, é que a relação dos itens a serem comprados chega no setor de licitações para dar andamento ao processo de aquisição. Então, o passo mais importante seria a correta descrição dos produtos sustentáveis e que estes possam atender demanda da secretaria. Assim, além da pouca capacitação dos funcionários do setor de licitações, os gestores responsáveis pelas secretarias não possuem uma grande preocupação na compra de produtos sustentáveis, talvez pelo desconhecimento da possibilidade de compra de itens que causem o menor dano ao meio ambiente.

Assim, o que se verifica é que ainda existe uma profunda despreocupação e pouco conhecimento em relação às compras sustentáveis. Identifica-se que o setor de licitação em si não é o responsável pelo desenvolvimento nacional sustentável através das compras públicas. Cabe mais aos gestores um bom planejamento de suas compras.

Bárbara (2016), também aponta que o pouco conhecimento a respeito da legislação e sobre critérios sustentáveis nas compras públicas, no 
que compete às especificações técnicas e a escolha do material, dificulta o atendimento do artigo $3^{\circ}$ da Lei de Licitações. O que se pode concluir que, a falta de capacitação é um dos maiores entraves da promoção das compras públicas sustentáveis.

Sobre a falta de capacitação e a atuação dos gestores serem os principais entraves das compras sustentáveis, Cunha e Araújo (2019) chegaram a esse mesmo resultado, quando afirmam que dentre outros aspectos, a capacitação, a atuação da gestão e a legislação são algumas das dificuldades encontradas no desenvolvimento de uma compra sustentável.

Corroborando esses resultados, Melo (2019), em pesquisa, concluiu que a realização de compras sustentáveis ainda é bastante inexpressiva. Reforça ainda que é urgente a necessidade de mudança da visão dos gestores e da cultura organizacional para prática da proteção ambiental em diversos setores da administração pública.

\section{CONSIDERAÇÕES FINAIS}

Apesar dos inúmeros esforços feitos em todo o mundo para reduzir os impactos ambientais e tornar o planeta mais sustentável, muito ainda falta a ser desenvolvido. Algumas medidas podem garantir mais desenvolvimento com foco na sustentabilidade. A situação ambiental é preocupante, pois os recursos naturais não renováveis estão propensos ao fim dentro de poucos anos. As gerações futuras estão comprometidas, já que o que se tem disponível na natureza pode não ser suficiente para suprir suas demandas.

Em meio a toda essa discussão surge o desenvolvimento nacional sustentável, garantido no artigo $3^{\circ}$, Lei 8.666/93, Lei de Licitações. Como o governo brasileiro gasta milhões com compras governamentais, ele se torna o principal responsável em fomentar as boas práticas de compras sustentáveis. Com uma gestão sustentável, o processo licitatório torna-se o meio pelo qual os governos podem atender a demanda de compras sustentáveis, garantindo sua função social e a proteção ao meio ambiente. 
Os funcionários do setor de licitações, os gestores públicos e os demais funcionários envolvidos no fluxo das despesas, carecem de cursos específicos para compras públicas sustentáveis, para só a partir daí começarem a aplicar esses conceitos e critérios nas compras locais.

Cabe salientar que é de suma importância a conscientização e sensibilização iminente dos gestores em relação ao tema, pois só assim as licitações poderão atender o que preceitua o artigo $3^{\circ}$ da Lei 8.666/93, que rege esses processos administrativos. Além de ser necessária a implantação da logística reversa para os materiais considerados perigosos e poluentes (lâmpadas, pilhas e baterias, materiais de informática, pneus, plásticos). Que de acordo com a Lei 12.305, de 2 de agosto de 2010, em seu artigo $3^{\circ}$ inciso XII, define logística reversa como "um conjunto de ações, procedimentos e meios destinados a viabilizar a coleta e a restituição dos resíduos sólidos ao setor empresarial, para reaproveitamento, em seu ciclo ou em outros ciclos produtivos, ou outra destinação final ambientalmente adequada" (BRASIL, 2010a). Assim, a implantação desse procedimento geraria o reaproveitamento de itens que seriam lançados no ambiente, dando novo destino ou um novo ciclo até seu destino.

É importante a necessidade de um estudo mais aprofundado em relação às licitações sustentáveis que englobem todas as licitações de prestação de serviços do município e, principalmente, as licitações de obras e serviços de engenharia civil, que causam grande impacto ambiental. Analisar os materiais e os sistemas, verificar a interferência no meio físico e na vida dos seres vivos que pertencem ao lugar.

Essa pesquisa se tornou de grande valor para perceber o quão deficiente, em relação à sustentabilidade ainda é o sistema de compras públicas do Município de Jaguaribe. O setor responsável ainda é falho em relação às licitações sustentáveis, nas quais pode se detectar que a falta de capacitação e planejamento são os principais fatores que impedem que as compras sustentáveis sejam efetivamente implantadas no Município. 


\section{REFERÊNCIAS}

AGUIAR, M. R. M. P.; NOVAES, A. C.; GUARINO, A. W. S. Remoção de metais pesados de efluentes industriais por aluminossilicatos. Química Nova, São Paulo, v. 25, n. 6B, p. 1145-1154, 2002. Disponível em: http:// bit.do/fJZXe. Acesso em: 27 abr. 2018.

ARAUJO, B. C. S.; SILVA, J. M. B.; WADA, R.; OLIVEIRA FILHO, S. R.. Tratamento de Efluentes Industriais. Revista Ciências do Ambiente On-Line, Campinas, v. 4, n. 2, p. 1-5, 2008. Disponível em: http://bit.do/ fJZXi. Acesso em: 2 out. 2018.

ARAÚJO, G. Licitação e contratos públicos. 2. ed. Fortaleza: Prêmios, 2009.

BÁRBARA, E. F. S. Subsídios para implantação de uma política institucional de compras sustentáveis na UFRB. 2016. Dissertação (Mestrado em Gestão de Políticas Públicas e Segurança Social) - Centro de Ciências Agrárias, Ambientais e Biológicas, Universidade Federal do Recôncavo da Bahia, Cruz das Almas, 2016. Disponível em: http://bit.do/ fJ2SV. Acesso em: $1^{\circ}$ out. 2020.

BARROSO FILHO, E. A. Licitações sustentáveis: a observância do critério de sustentabilidade em conformidade com os parâmetros de competitividade, economicidade e proporcionalidade. 2012. Monografia (Especialização em Direito Administrativo) - Instituto Brasiliense de Direito Público, Brasília, DF, 2012.

BRASIL. Advocacia-Geral da União. Guia nacional de contratações sustentáveis. 3. ed. Brasília, DF: AGU, 2020. 
BRASIL. Constituição da República Federativa do Brasil, de 5 de outubro de 1988. Brasília, DF: Presidência da República, 1988. Disponível em: http://bit.do/fJZXy. Acesso em: 2 nov. 2017.

BRASIL. Decreto $n^{\circ} 7.746$, de 5 de junho de 2012. Regulamenta o art. $3^{\circ}$ da Lei $n^{\circ} 8.666$, de 21 de junho de 1993, para estabelecer critérios e práticas para a promoção do desenvolvimento nacional sustentável nas contratações realizadas pela administração pública federal direta, autárquica e fundacional e pelas empresas estatais dependentes, e institui a Comissão Interministerial de Sustentabilidade na Administração Pública - CISAP. Diário Oficial da União, Brasília, DF, 6 jun. 2012a. Disponível em: http://bit.do/fJZXG. Acesso em: 12 nov. 2017.

BRASIL. Decreto $n^{\circ} 7.840$, de 12 de novembro de 2012. Estabelece a aplicação de margem de preferência em licitações realizadas no âmbito da administração pública federal para aquisição de perfuratrizes e patrulhas mecanizadas, para fins do disposto no art. $3^{\circ}$ da Lei ${ }^{\circ} 8.666$, de 21 de junho de 1993. Diário Oficial da União, Brasília, DF, 13 nov. 2012 b. Disponível em: http://bit.do/fJZXJ. Acesso em: 12 nov. 2017.

BRASIL. Decreto $n^{0} 7.843$, de 12 de novembro de 2012. Estabelece a aplicação de margem de preferência em licitações realizadas no âmbito da administração pública federal para aquisição de disco para moeda, para fins do disposto no art. $3^{\circ}$ da Lei n ${ }^{\circ} 8.666$, de 21 de junho de 1993. Diário Oficial da União, Brasília, DF, 5 dez. 2012c. Disponível em: http://bit.do/ fJZXL. Acesso em: 12 nov. 2017.

BRASIL. Decreto $n^{\circ} 9.178$, de 23 de outubro de 2017. Altera o Decreto $n^{\circ}$ 7.746 , de 5 de junho de 2012, que regulamenta o art. $3^{\circ}$ da Lei $n^{\circ} 8.666$, de 21 de junho de 1993, para estabelecer critérios, práticas e diretrizes para a 
promoção do desenvolvimento nacional sustentável nas contratações realizadas pela administração pública federal direta, autárquica e fundacional e pelas empresas estatais dependentes, e institui a Comissão Interministerial de Sustentabilidade na Administração Pública - CISAP. Diário Oficial da União, Brasília, DF, 24 out. 2017. Disponível em: http://bit.do/ fJ2Zy. Acesso em: 4 out 2020.

BRASIL. Instrução Normativa ${ }^{\circ}$ 6, de 15 de março de 2013. Aperfeiçoa o escopo de serviços prestados pelo Cadastro Técnico Federal de Atividades Potencialmente Poluidoras e Utilizadoras de Recursos Ambientais. Diário Oficial da União, Brasília, DF, 11 abr. 2013. Disponível em: http://bit.do/ fJZYe. Acesso em: 3 out. 2018.

BRASIL. Lei $n^{\circ}$ 8.666, de 21 de junho de 1993. Regulamenta o art. 37, inciso XXI, da Constituição Federal, institui normas para licitações e contratos da Administração Pública e dá outras providências. Diário Oficial da União, Brasília, DF, 6 jul. 1993. Disponível em: http://bit.do/fJZYk. Acesso em: 2 nov. 2017.

BRASIL. Lei $n^{\circ} 10.520$, de 17 de julho de 2002. Institui, no âmbito da União, Estados, Distrito Federal e Municípios, nos termos do art. 37, inciso XXI, da Constituição Federal, modalidade de licitação denominada pregão, para aquisição de bens e serviços comuns, e dá outras providências. Diário Oficial da União, Brasília, DF, 18 jul. 2002. Disponível em: http://bit.do/fJZYs. Acesso em 2 nov. 2017.

BRASIL. Lei ${ }^{\circ} 11.079$, de 30 de dezembro de 2004. Institui normas gerais para licitação e contratação de parceria público-privada no âmbito da administração pública. Diário Oficial da União, Brasília, DF, 31 dez. 2004. Disponível em: http://bit.do/fJZYt. Acesso em: 12 nov. 2012. 
BRASIL. Lei ${ }^{\circ} 12.305$, de 2 de agosto de 2010. Institui a Política Nacional de Resíduos Sólidos; altera a Lei no 9.605, de 12 de fevereiro de 1998, e dá outras providências. Diário Oficial da União, Brasília, DF, 3 ago. 2010a. Disponível em: http://bit.do/fJZYy. Acesso em: 12 jun. 2018.

BRASIL. Lei $\mathrm{n}^{\circ} 12.349$, de 15 de dezembro de 2010 . Altera as Leis $\mathrm{n}^{\circ}$ 8.666, de 21 de junho de $1993,8.958$, de 20 de dezembro de 1994, e 10.973, de 2 de dezembro de 2004; e revoga o $\S 1^{\circ}$ do art. $2^{\circ}$ da Lei 11.273, de 6 de fevereiro de 2006. Diário Oficial da União, Brasília, DF, 16 dez. 2010b. Disponível em: http://bit.do/fJZYF. Acesso em: 8 nov. 2017.

BRASIL. Portaria 23, de 12 de fevereiro de 2015. Estabelece boas práticas de gestão e uso de energia elétrica e de água nos órgãos e entidades da Administração Pública Federal direta, autárquica e fundacional e dispõe sobre o monitoramento de consumo desses bens e serviços. Diário Oficial da União, Brasília, DF, 13 fev. 2015. Disponível em: http://bit.do/fJZYX. Acesso em: 12 nov. 2017.

BRASIL. Portaria 61, de 15 de maio de 2008. Estabelece práticas de sustentabilidade ambiental a serem observadas pelo Ministério do Meio Ambiente e suas entidades vinculadas quando das compras públicas sustentáveis e dá outras providências. Diário Oficial da União, Brasília, DF, 2008. Disponível em: http://bit.do/fJZYN. Acesso em: nov. 2017.

CAVALCANTI, C. Meio ambiente, Celso Furtado e o desenvolvimento como falácia. Ambiente \& Sociedade, Campinas, v. 5, n. 2, p. 73-84, 2003. Disponível em: http://bit.do/fJZZc. Acesso em: 31 out. 2017.

CEARÁ. Criado Oficialmente o Selo Empresa Sustentável. Secretaria do Meio Ambiente, Fortaleza, 19 dez. 2019. Disponível em: http://bit.do/ fJZZH. Acesso em: 2 out. 2020. 
CEARÁ. Resolução Administrativa 3/2019. Diário Oficial do Tribunal de Contas do Estado do Ceará, Fortaleza, 12 fev. 2019. Disponível em: http://bit.do/fJZZi. Acesso em: 2 out. 2020.

CUNHA, S. F.; ARAÚJO, M. A. D. Barreiras e aspectos facilitadores para implementação das licitações sustentáveis no IFPB - Campus Campina Grande. Latin American Journal of Business Management, Taubaté, v. 10, n. 2, p. 24-37, 2019. Disponível em: http://bit.do/fJ2Td. Acesso em: 4 out. 2020.

CYPRESTE, A. S. T. Licitações sustentáveis, instrumento legal de promoção da sustentabilidade: um estudo da aquisição de bens na Universidade Federal do Espírito Santo - UFES. 2013. Dissertação (Mestrado Profissional em Gestão Pública) - Centro de Ciências Jurídicas e Econômicas, Universidade Federal do Espírito Santo, Vitória, 2013. Disponível em: http://bit.do/fJZXt. Acesso em: 2 out. 2020.

FERNANDES, J. U. J. O governo contratando com os pequenos negócios: o Estatuto da Micro e Pequena Empresa fomentando a economia do país. Brasília, DF: Sebrae, 2013.

FIRJAN. Manual de licenciamento ambiental: guia de procedimento passo a passo. Rio de Janeiro: GMA, 2004. Disponível em: http://bit.do/ fJZXP. Acesso em: 27 abr. 2018.

FURTADO, M. R.; FURTADO, M. R. R. Licitações sustentáveis: como fazer? Revista Fórum de Contratação e Gestão Pública, Belo Horizonte, n. 126, p. 69-72, 2012.

GIL, A. C. Métodos e téenicas de pesquisa social. 6. ed. São Paulo: Atlas, 2008. 
JAGUARIBE (CE). Edital de licitação da Prefeitura Municipal de Jaguaribe. Pregão Presencial n ${ }^{\circ}$ 24.01.02/2017. [Aquisição de equipamento e material permanente para o hospital municipal, junto a secretaria de saúde de Jaguaribe/CE]. Diário Oficial do Município de Jaguaribe, Jaguaribe, n. 2445, p. 1, 2017. Disponível em: http://bit.do/fJZZr. Acesso em: 27 abr. 2018.

LEAL, V. M. G. A questão ambiental e a administração pública: um estudo de caso. 2011. Monografia (Curso de Altos Estudos de Política e Estratégia) - Escola Superior de Guerra, Rio de Janeiro, 2011. Disponível em: http://bit.do/fJ2Ze. Acesso em: $1^{\circ}$ ago. 2018.

LIMA, M. L. B.; FROTA, J. A.; ARAÚJO, F. S. M.; FONTENELE, R. E. S. Desenvolvimento sustentável e competitividade das nações: uma análise multivariada. Reuna, Belo Horizonte, v. 22, n. 1, p. 41-62, 2017. Disponível em: http://bit.do/fJZZt. Acesso em: 31 out. 2017.

LUCENA, K. A. A. Práticas de sustentabilidade relacionadas ao processo de compras no Instituto Federal de Educação, Ciência e Tecnologia de Pernambuco - Campus Cabo de Santo Agostinho. 2016. Dissertação (Mestrado em Gestão do Desenvolvimento Local Sustentável) - Faculdade de Ciências da Administração de Pernambuco, Universidade de Pernambuco, Recife, 2016. Disponível em: http://bit.do/fJ2SB. Acesso em: 2 out. 2020.

MELO, J. M. Análise da aplicabilidade das licitações sustentáveis no âmbito da Universidade Federal de Campina Grande. 2019. Dissertação (Mestrado em Sistemas Agroindustriais) - Centro de Ciência e Tecnologia Agroalimentar, Universidade Federal de Campina Grande, Pombal, 2019. Disponível em: http://bit.do/fJ2UY. Acesso em: 27 set. 2020. 
NASCIMENTO, L. F. Gestão ambiental e sustentabilidade. 2. ed. Florianópolis: Departamento de Ciências da Administração/UFSC. 2012.

OLIVEIRA, A. C. Gestão ambiental no serviço público. 2008. Monografia (Especialização em Gestão Pública) - Instituto a Vez do Mestre, Universidade Cândido Mendes, Rio de Janeiro, 2008. Disponível em: http://bit.do/fJZZB. Acesso em: 31 out. 2017.

PINHEIRO, M. G. As compras públicas sobre o viés da sustentabilidade no âmbito das licitações sustentáveis. Revista Negócios Públicos, Curitiba, v. 113, p. 14-20, 2013.

PRODANOV, C. C.; FREITAS, E. C. Metodologia do trabalho científico: métodos e técnicas da pesquisa e do trabalho acadêmico. 2. ed. Novo Hamburgo: Feevale, 2013. Disponível em: http://bit.do/fJZZF. Acesso em: 22 fev. 2018.

VICENTINI. V. J. Licença ambiental ato administrativo que impõe e assegura o cumprimento dos princípios e normas do Direito Ambiental. 2019. Monografia (Bacharelado em Direito) - Centro Universitário Presidente Antônio Carlos, Barbacena, 2019. Disponível em: http://bit.do/ fJ4qq. Acesso em: $1^{\text {o }}$ out. 2020. 